from the printed page, and all other white paper lying on the table, dries the eyes, the lids, the forehead, and temples, Temporary relief may be found by bathing the face and eyes in water, but it is only temporary. The hot, dry air about the lamp is also harmful, and no doubt contributes its share of injury to the vision. These evils may both in part be remedied by placing a pane of glass so as to intercept the rays from the lamp before they strike on the book or the face. But it must be placed at such a distance from the lamp as not itself to become heated.

The hotter the flame, the whiter it is, and the more light is thrown off in proportion to the heat. Hence oculists are recommending such lights as the Student's and Moderator lamps, which burn with a small, hot, and very brilliant flame, as compared with that furnished by the Argand and fish-tail burners. We learn from statistics how alarmingly prevalent near-sightedness has become of late among students. Hence anything which will tend in the future to prevent this wide-spread defect will be boon to mankind. And here is where the particular advantages of electricity come to the front. The fact that there are no gaseous products to radiate heat without light, taken together with the high temperature of the incandescent carbon, unite to give us the maximum of light with the minimum of heat. The evcr-varying intensity of the arc light is at present a strong objection to it, but we may look forward to the success of the light from the incandescent carbon strip, in the near future, with the assurance that we shall soon have a remedy for the most wide-spread evil that afflicts the human vision.

Boston, Mass., U.S.A.
W. H. PICKERING

\section{THE GREAT NEBULA IN ANDROMEDA}

$\mathrm{F}^{\mathrm{EW}}$ objects in the heaven save been treated with such unmerited neglect as this which has not inaptly been termed the Queen of the Nebulæ. Notwithstanding its enormous magnitude, spreading out, as followed by the Harvard I5-inch achromatic, to $24^{1}$ in length, (according to Bond-Trouvelot gives more), with a breadth of upwards of $I^{\circ}$; and its conspicuous brightness, readily perceptible with the naked eye, it has received little com.

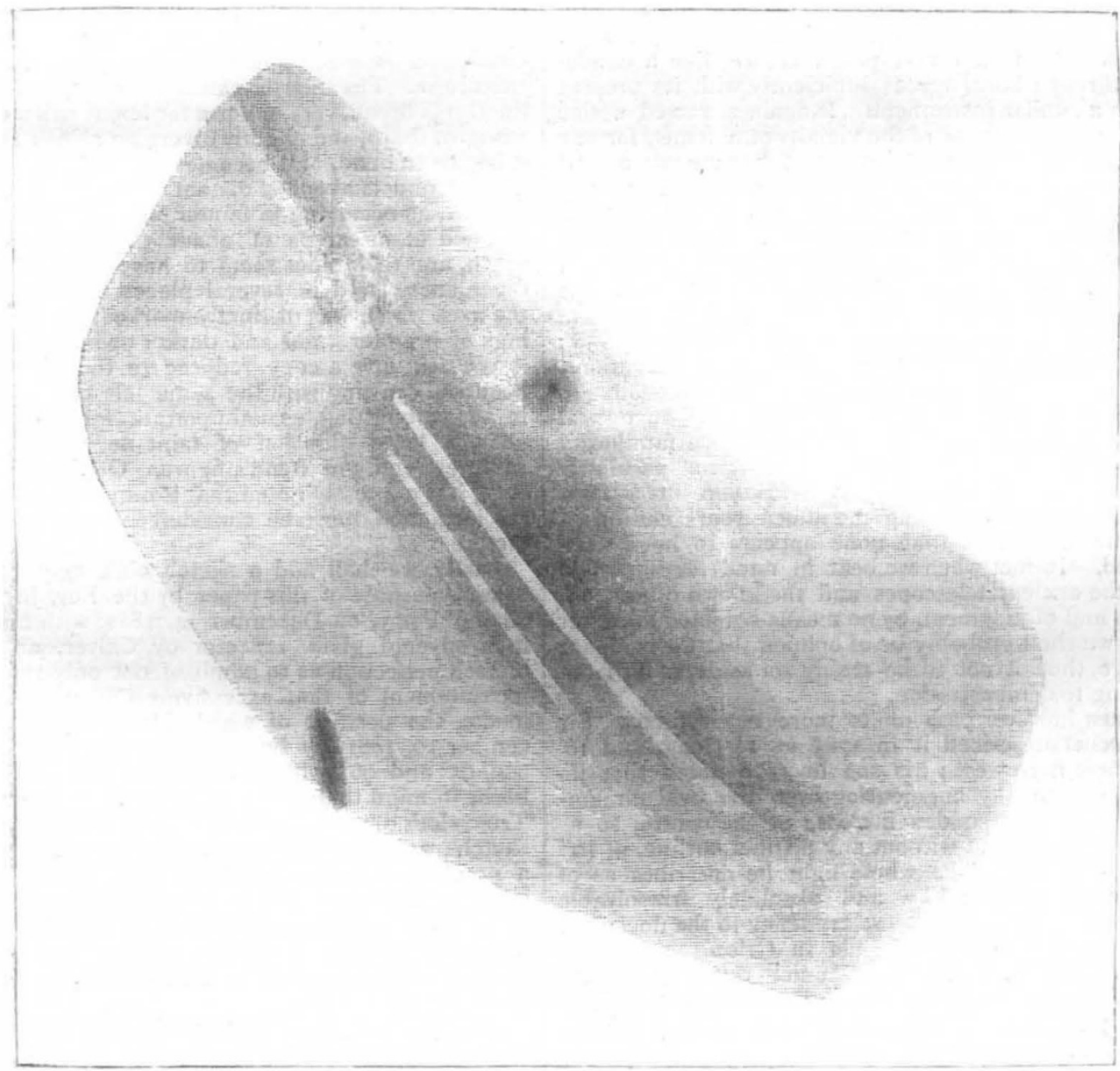

FIG. I. - Bond, 1847 .

parative notice. The reason probably may be the pertinacity with which it has hitherto resisted all inquiry, and defied the efforts of the most powerfully armed investigation; so that it seems to have been left on one side, as too unpromising for more than casual inspection.
This however bears the character of a premature conclusion. Direct examination by the most powerful telescopes has done very little to solve the mystery of its nature. The reply extorted by the spectroscope is but partially intelligible. But we must not therefore despond. 
The negative or ambiguous results hitherto obtained do not preclude-on the other hand they rather inviteattempts of a different kind. If again defeated, we are only where we were before. If in any measure successful, we may indeed find the mystery only increased by partial solution ; but such, after all, is the progress and the limit of all earthly knowledge. An obvious line of inquiry presents itself in the present instance, which seems not to have been adverted to in modern times-the possible evidence of variation either in form or brightness; and the following notices, neither as exhaustive nor as minute as the subject would otherwise admit, have been chiefly put together with this view.

The history of this nebula, which includes the ancient evidence, such as it is, of variation, is in brief as follows.

The first mention of it, according to the late Prof. G. P. Bond, the eminent observer at Harvard College, Cambridge, U.S. America, to whose memoir we shall be indebted for a considerable portion of our materials, occurs in an ancient star-catalogue with charts, supposed to date back as far as the close of the tenth century, ${ }^{1}$ where it is represented of an oval form. Its previous omission in ancient catalogues is more easily accounted for than the remarkable silence of Tycho Brahe and Bayer. Marius (Mayer) in 1612 was the first to apply to it the recently invented telescope; his description of whitish rays, brightening to a dull and pallid centre, like a candle shining throug' horn, agrees sufficiently with its present aspect in a similar instrument. It again attracted notice in 1664 , in consequence of the vicinity of a comet, for one of which bodies it has been several times mistaken, and it has never since been lost sight of, though Bouillaud thought its brightness variable between $\mathrm{I} 664$ and $\mathrm{I} 666$. In $1676 \mathrm{Kirch}$ was of a similar opinion. Cassini in 1740 described it somewhat unaccountably as nearly triangular. Mairan in 1754 endorsed the description of Marius. Le Gentil in 1749 observed it circular and of uniform density ; but oval, with central condensation, in $1757-58$; and, from a consideration of all the known observations, believed it variable, without, however, being insensible to the differences arising from the inequality of optical means. Messier, on the other hand, whose familiarity with cometary phenomena rendered him a peculiarly competent witness, perceived no variation in a form similar to the present during the fifteen years ending in $177 \mathrm{I}$; and since that time none appears to have been suggested. In fact when we bear in mind the imperfection of the ancient telescopes, and the known differences of vision and of judgment, by no means confined to earlier periods, we shall probably be of opinion that the evidence of change, though not to be rashly set aside, is far from amounting to demonstration.

We must however pass on to more recent times. Sir W. Herschel described it in $I 785$ as $I \frac{1^{\circ}}{2}$ long, and $I 6^{\prime}$ broad where narrowest; his son in 1826 noted that $j$ ts brightness, gradually augmenting from the oval circumference, receives a sudden increase at the centre, so as to form a nucleus, but without any distinct outline, of $\mathrm{IO}^{\prime \prime}$ or $12^{\prime \prime}$ in diameter. The whole light he describes as of the most perfectly milky and absolutely irresolvable character, without the slightest tendency to the flocculent appearance of the Great Nebula in Orion. Ten years afterwards Lamont, with the Munich refractor of 11.2 (? English) inches, and a power of 1200 , found the nucleus, of about $7^{\prime \prime}$, longish in form, composed of very minute granulations, but without resolution.

Thus matters stood till July, 1847, when, soon after its erection, the great Merz acbromatic of Harvard College was brought to bear upon it, with the confirmation of the almost star-like nucleus, but, owing no doubt to the unfavourable background of the summer sky, it was not till September 14 that the two dark rifts or canals were

\footnotetext{
The Persian astronomer Sûfi, Flammarion informs us, referred to it about the same period as a well-known object.
}

detected, which form so strange and peculiar a feature in this grand object. But no resolution was attained. It was estimated that owing to the light and sharpness of this admirable instrument upwards of 1500 stars were visible within the limits of the nebulosity, without the least apparent connection with it. And on which side they may lie who will presume to say?

We may now give a reduction from the drawing of Prof. G. P. Bond, adequate to our present purpose, though, from the difference of material, far inferior in delicacy to the original steel engraving. Great pains were taken in delineation, and numerous measures were obtained from the divided circles of the instrument; but an important admission of his must be borne in mind as to possible error in the comparative brightness of the different regions.

The drawing includes, it will be observed, two bright patches, one on either side of the grand central mass, but each involved in its diffusion, and therefore presumably, though not demonstrably, a part of the same complex structure. The more distant one below to the left, or north-preceding (for our diagrams give the inverted or telescopic view), was discovered by Caroline Herschel in 1783, and is known as HVI8, or No. 105 in the General Catalogue of Nebulæ. The other attendant, pointed out by Le Gentil, No. 32 in Messier's, $y_{17}$ in the General Catalogue, is much smaller, but brighter, and of a circular form. The interior canal is the longer and more distinct, $I^{\frac{1}{2}}$ ' broad, very uniform for about half a degree, with straight, sharp, and slightly diverging sides; further north it begins to bend, and becomes fainter and less regular. The second is about $4^{\prime}$ distant from it, shorter, and less distinct, as occurring in fainter light. The two rifts are inclined at an angle of about $3^{\circ}$, opening towards the north, and their sides seem to have a common point of divergence; and in several places along the course of the axis, which was distinctly marked, there were gatherings of brighter knots and darker openings.

We next give a copy, reduced to the same scale, of a beautiful drawing with the same telescope by Trouvelot, in 1874 ; omitting, as unimportant for our present purpose, a large diffusion of faint nebulosity beyond the south extremity of Bond's figure. Of this drawing, however, it is expressly noted that it only gives a good general idea, and must be considered not as a map, but a picture.

Lastly, we shall add a sketch obligingly made for the express purpose of this paper by the Rev. Jevon J. Mus champ Perry, on December 14, 188 I, with his great $18 \frac{1}{4}-$ inch silvered glass reflector by Calver, an instrument of such perfection as to admit of not only separation, but measurement of that excessively difficult pair $\gamma^{2}$ Andromedæ, the position of which Mr. Perry found, on December 10, I88I, by two measurements with a power of $600,95^{\circ}$ and $96^{\circ}$, with a distance of $0^{\prime \prime} \cdot 3 \cdot{ }^{x}$ It nuust be borne in mind that this is not, like Bond's and probably Trouvelot's drawings, a combination of results, but a single sketch; according, however, precisely with one taken on a previous night, and it is no less material to add that subsequent examination in clearer air revealed, as might be expected from the light-grasp of such an instrument, a much greater extension of nebulosity in every direction, equal, as it would seem, to that shown in the American observations.

In these two views taken with the same instrument after an interval of twenty-seven years, and a third six years later with a telescope of fairly equivalent power, we have before us the materials of an interesting comparison. The general similarity is obvious; but there are variations which it may not be well to ignore. One is, the form of the principal mass of light, spindle-shaped in

I The agreement is remarkable, in so close an object, with one of the Washington measures, $1880^{\circ} 039,95^{\circ} 8,0^{\prime \prime} .35$; their average for three years being $101^{\circ}, 0^{\prime \prime} \cdot 35^{8}$ 
the earlier, globular in the two later drawings. This difference, while reminding us of the ancient variations of Le Gentil, may possibly not imply much, where no distinct outline is presented to rectify the judgment of the eye. But we have something more tangible in the length and form of the canals. Here, assuming equal care on the part of Trouvelot in designing, with that claimed by Bond both in delineation and description, we seem to have indications of change. It is true that Bond's account of the outer or shorter canal, as commencing a few minutes $n p$ the other, does not altogether agree with his drawing; but this is not the sole instance of confused "orientation" in his memoir; and at any rate he describes its commencement as only $4^{\prime}$ of space distant from the other. Trouvelot, as will be seen, has extended it much further $s p$; and should it be objected that this slenderer termination may have escaped the eye of Bond, it is curious to find it strongly and independently confirmed by Perry in two sketches on different nights, and by his express statement that "the $\phi$ rift extends further than the $f$ rift on the southern side." The greater breadth which he has given in each sketch to both canals is also worthy of notice. Another point of disagreement between Bond and Trouvelot occurs in the form of the longer canal : the " perfectly straight, suddenly terminated, and slightly diverging "sides, as far as the nucleus, of Bond's description, confirmatory of his drawing, according ill with the sinuous direction which Trouvelot has shown.

This may suffice for the collation of the results obtained by great instruments. But a comparison yet remains with the appearance in smaller telescopes; and it will be found deserving of attention. Let our aperture be restricted to 5 inches achromatic, or an equivalent light in a reflector: then, with ordinary vision and customary skies, the three salient points, the great centre, Le Gentil's ball, and Caroline Herschel's cloud, though much dimmed and contracted, keep their places, but all the attendant nebulosity will be swept away. Such at least is my own experience. On October 5, 1863, a few hours before the strong earthquake-shock, that will long be remembered in this part of England, I caught a portion of the inner canal with a $5^{\frac{1}{2}}$ inch achromatic, and on August 24, I864, I saw them both feebly, but certainly, with 8 inches of silvered glass, and have several times followed them with that mirror, and with my present $9 \frac{1}{3}$ inch aperture, for a considerable length: but though traced, I cannot say that they would have been discovered. And latterly, whether from decay of visual power, or want of purer air, I have failed to detect them. But the general result is unmistakable. Either Bond's drawing must have exaggerated -and that materially-the light which they traverse or that light must have since faded. The latter it must be owned is not probable. Yet his figure is fairly supported by his words, where he gives both canals near the nucleus as "beautifully distinct," and the light between them 2 as bright as on the inner side of the longer one, and his design makes both rifts cleave, not as now, the feeble diffusion, but the great mass, not far from its very heart. On the other hand it must be admitted that probably at a not much later date, Lord Rosse's 3 -foot speculum showed a much greater contrast between the opposite sides of that canal; and Trouvelot comes much nearer to the present aspect of things: so that nothing very satisfactory can be deduced here. The case however may seem stronger with regard to Caroline Herschel's nebula. There are discrepancies in the earlier values of its light. Her brother called it "pretty faint" with an area of $30^{\prime} \times 12^{\prime}$, proving that he included with it much of the great nebula. His son, reducing it to $15^{\prime} \times 7^{\prime}$, found it "pretty bright," though it stands as "very bright" in the General Catalogue. Bond shows it of a brilliancy superior to all but the light near the great nucleus and the centre of Le Gentil's ball. The Earl of Rosse, with the 6 -foot mirror in 1876 complains of this delineation as "far too bright and sharply defined." Trouvelot again with a softer general effect has a small centre as bright as Bond; and this may perhaps be the nucleus faintly suspected by Sir John Herschel, and described by Lord Rosse in 1855 as bright and sharp : while the cautious and accurate d'Arrest (186 [-67) using an II-inch object-glass, and giving its size $I 2^{\prime} \times 2 \frac{1}{2}^{\prime}$, speaks of it as only moderately bright, much more so towards the centre, but without a genuine nucleus. These details, needless and tedious as they may possibly at first appear, are introduced chiefly from their bearing on our present inquiry as to the probability of change, but in some measure as illustrative of the uncertainty that hangs about such observations. Every one may not be aware of the breadth of margin required, where there is no distinct outline, and faint diffusions fade out of all but the purest skies, and dilate and shrink by turns under the anxious gaze, and estimates of brightness are precarious, and artistic talent is often dissociated from the observer's skill. But after all allowances there can be no doubt that the existing aspect of this (Miss Herschel's) nebula with moderate telescopes is much less reconcilable with the designs of Bond and Trouvelot than might have been expected.

We can neither at present push this line of inquiry further, nor say that it has been very successful. Had it yielded us distinct evidence of change either in form or brightness, it must of course have been accepted as decisive against a stellar constitution; but we have only met with such probabilities as invite close and long research; and it was with a view of stimulating such research that the present paper was undertaken. A few more remarks may be permitted to render it less incomplete.

We stated originally that no resolution has ever been effected. This seems und subted as to the grand mass. ${ }^{1}$ The Earl of Rosse had indeed thought such development approaching with the 3 -foot mirror, but only from an aspect presented also by the Dumb-bell and Ring nebulæ, since known to be gaseous; and the 6-foot giant broke down in its turn : and Newconb has remarked that "in the most powerful telescopes the light fades away so softly and gradually that no such thing as resolution into stars seems possible. Indeed, it looks less resolvable and more like a gas in the largest telescopes than in those of moderate size." But there is less unanimity as to the two companions. Bond expressly states that under high powers 105 appeared to be a coarse cluster of stars. The 6-foot at Parsonstown on the contrary effected no such result; and we may remember that Bond had imagined momentary resolution in the Orion nebula. As to the bright ball, the Herschels and Bond lay no claim to success; the latter only remarking that the field preceding it contained multitudes of very small stars on a very even milky nebulous ground. Lord Rosse's 3-foot gave it resolvable; the 6 -foot was silent.

D'Arrest once says, "nucleus stellatus circa medium"; at other times finds a nucleus equalling a 9 or $10 \mathrm{mag}$. star. ${ }^{2}$ It has been thought resolvable by Buff ham, and I believe by Key, and has certainly that aspect in my $9 \frac{1}{3}$ inch speculum. But even were these two companions found to be of a starry nature, their connection with the principal mass (though in the case of 105 supposed by Bond to be indicated by a line of stars) would yet remain to be demonstrated. It may be improbable, but it is not impossible, that each may be a case of mere optical juxtaposition.

The telescope has comparatively failed. But the spectroscope remains-an instrument as superior in analytical as it is inferior in optical power. And here we get

I It is very remarkable that the usually accurate Humboldt should have so misapprehended Bond's meaning as to consider the 1500 stars scattered over the nebulous area as a proof of the resolution which he expressly disclaims. A similar appearance is so often ascribed in these beautiful observations the centres of nebula, as to induce a suspicion of peculiarity, either cf vision or of structure; in the latter case worthy of future attentiun. 
some kind of reply; but still, except in one respect, an again, as a fresh point of resemblance in general unlikeindecisive one. It precludes at once the idea of a ness, M I3, as well as our two nebulæ in Andromeda, is simple gaseous condition such as that of the Ring said by Huggins to have its continuous spectrum crossed Nebula, or the Dumb-bell, or the wonder in Orion: either by lines of absorption or bright lines. So strange d'Arrest eomplains indeed of the feebleness of the principal spectrum; but all the three are continuous, as from stars. And yet they are peculiar, being deficient at the red end ; at least this is expressly stated as to the central mass and the little ball. This peculiarity reappears elsewhere, not only among others in the beautiful nebula M 81 and 82, in Ursa Major, which are as yet unresolved, but in the great Hercules cluster M I3, and surely indi- If gaseous, gas unknown, or in some hitherto un-
cates some difference from ordinary stellar light. And known condition, or as Newcomb remarks, under an

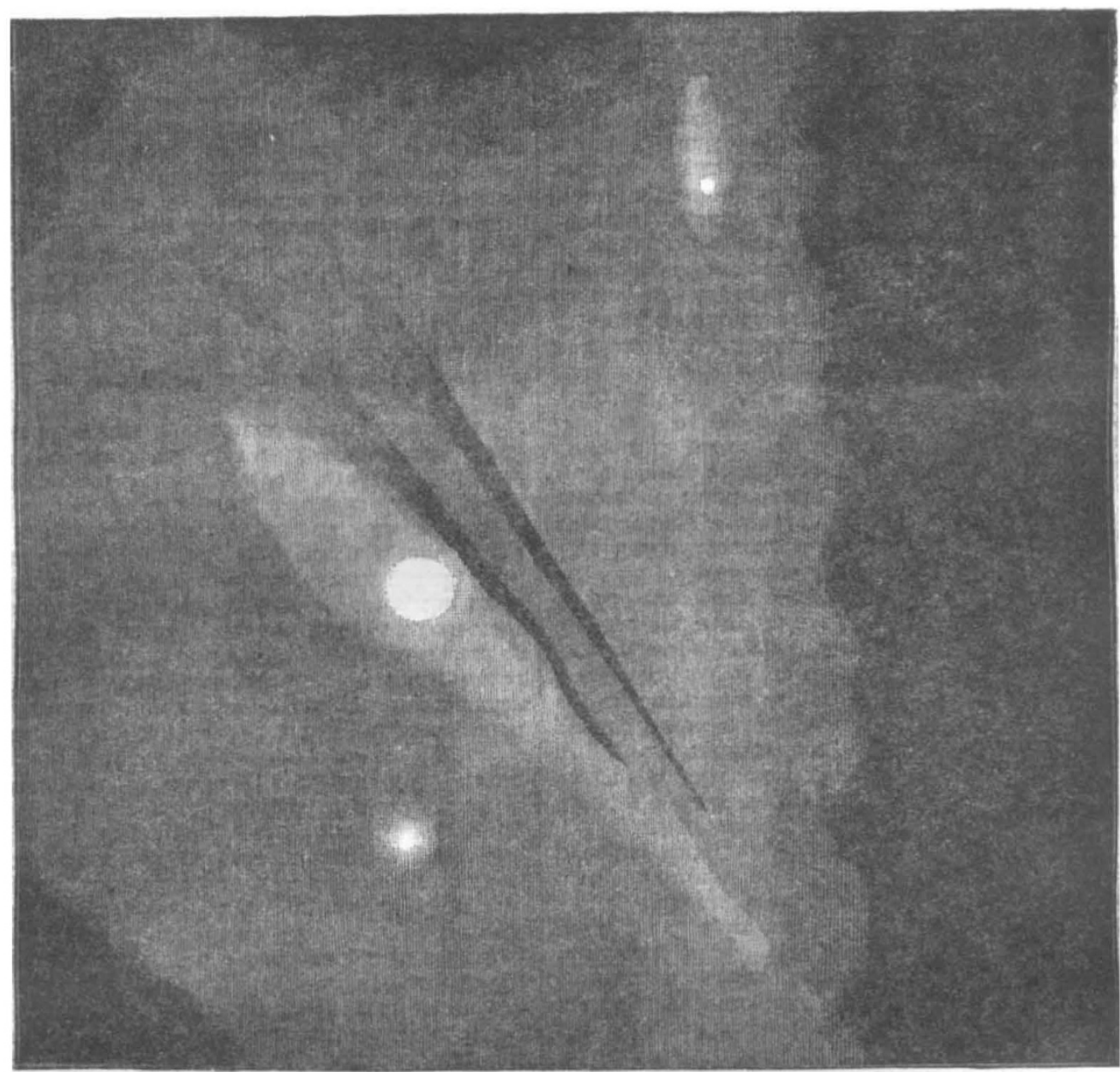

F1G. 2. -Trou : elot, 1874 .

unintelligible amount of pressure. If stellar, how are its components so concealed, that neitber in its extreme brightness, surpassing much, as I have especially noted, the great Crion nebula, nor in the evanescent faintness of its wide diffusion can they be insulated? If stars are there they must be numbered by hundreds of thousands; yet possibly of much lesser magnitude than we, from ancient habit, are apt unconsciously to associate with the idea of a star. The examination at least of many globular clusters has swept away old notions of size as well as distance; and there is no reason why bodies should not exist, not larger than the planets of our system, but emitting unborrowed light. And if such speculations may seem improbable, we may did this appear to that great observer that he was inclined to think in 1866 that perhaps the bright points in some clusters might not be of the same nature with true stars. At any rate the mystery, so far from being solved, seems only to be removed to a more inaccessible distance. What is that at which we gaze, overspreading field after field of the telescope with soft yet often vivid light? If gaseous, gas unknown, or in some hitherto un- 
could be their origin? And how far are they shown to other side of the stars so profusely scattered throughout be unalterable?

And, in the last place, what is the distance or real magnitude of that luminous mass? Is it on this or the the same visible area? It may be nearer, or, more correctly speaking, less unimaginably distant, than we are apt to suppose. It might even show sensible parallax, if

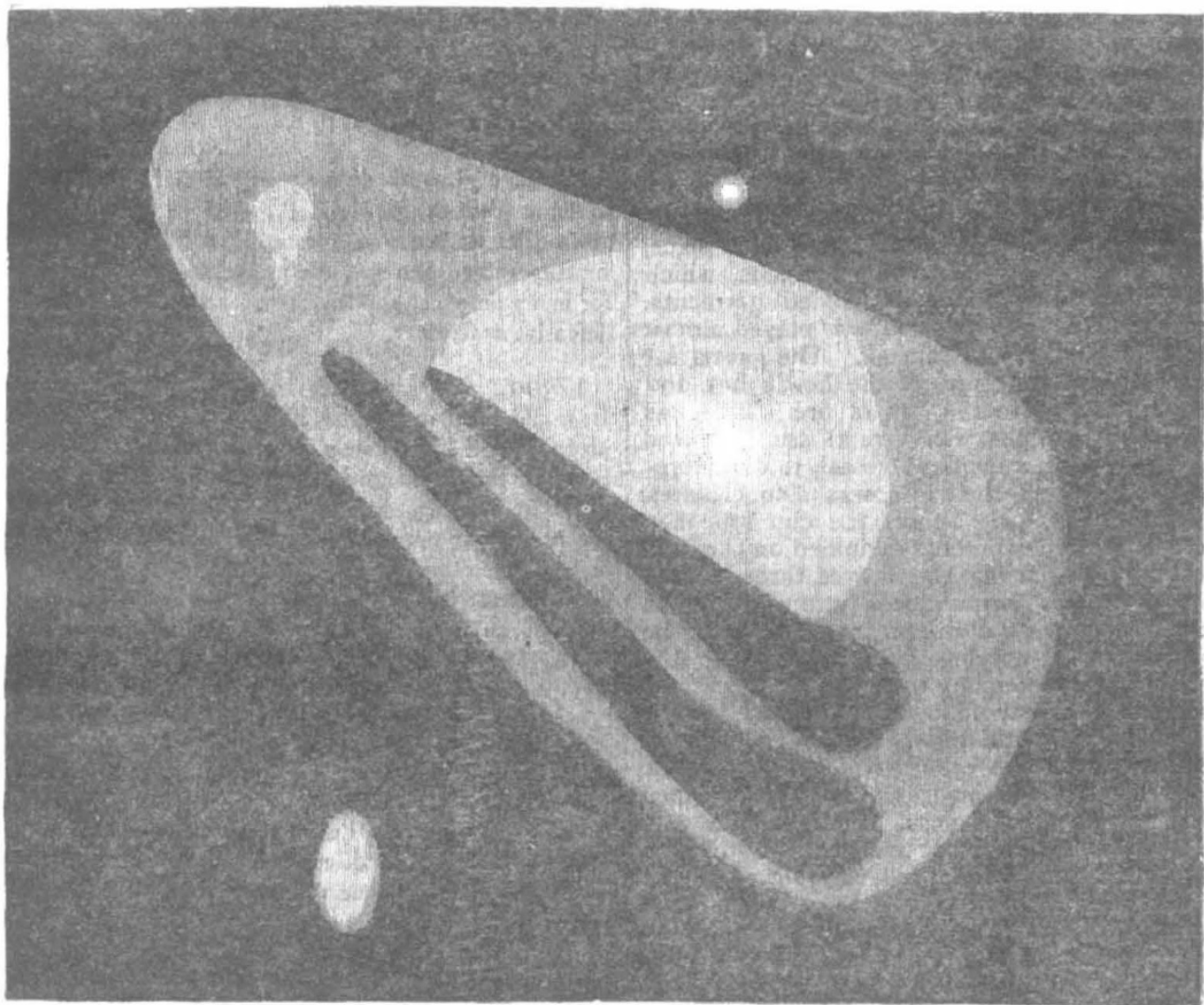

F1G. 3.-Perry, $\mathbf{1 8 8 \pi}$

d'Arrest's stellar point in II 7 could be compared in position with neighbouring stars; and even so, an enormous extent must still be assigned to it. Or it may lie yet further away in the unfathomable depths of space, expanded to a gigantic size-the largest body in the visible universe-the greatest display as to magnitude of its incomprehensible Creator.

And with these inquiries as to a mystery never in all probability to be penetrated by man, our imperfect remarks shall close.
T. W. WEBP

\section{A BEAR FESTIVAL AMONG THE AINOS}

A LTHOUGH it is well known that the Ainos of Yeso $A$ worship the bear, and have a festival known as the " bear-festival," at which that animal is killed, no foreign writer, except the one whom we are about to mention, has ever actually beheld this ceremony. Dr. Scheube, of Kioto, in a paper recently published in the Mittheilungen der deutschen Gesellschaft für Natur und Völker-kunde Ostasiens, describes one at wbich he was an honoured guest. He observes that these celebrations are becoming rarer every day; in the various villages which he visited there had not been one for some years. The motives assigned for this cessation of an old custom, is that the Ainos are becoming Japanised, and that the expenses are too great. In those parts of the island where Japanese habits have penetrated most, the absence of the skulls of the bears, which are also objects of veneration, is very ${ }_{4628} 6$ (Aquar Gaseous). The first of these I have seen well with my $9 \frac{1}{3}$-inch speculum. noticeable; and as the individual who gives a bear-feast is compelled to invite all his relations, friends, and neighbours, and to supply them with unlimited quantities of $s a k e$ (rice-beer)-a beverage which is three times mane expensive in Yeso than in Japan-the excuse on the score of expense is probably a valid one. It is, it. seems, incorrect to say that the Ainos reverence. the bear as they do their gods-the god of the fire or of the sea, for instance; but they respect the bear above all other animals. $\mathrm{He}$ is most useful to them; be supplies them with food, raiment, and even with medicine. On the other hand, when enraged, the bear is a terrar to them; he destroys their houses, plantations, and domestic animals, and kills themselves. The animal intended for sacrifice is selected while it is still very young, towards the end of winter, it is nourished by the wife of its owner at first, and when it gets stronger is fed on fish alone. In the beginning it runs freely about the house, but as it increases in size and strength it is placed in a cage. About September or October, when it is a 